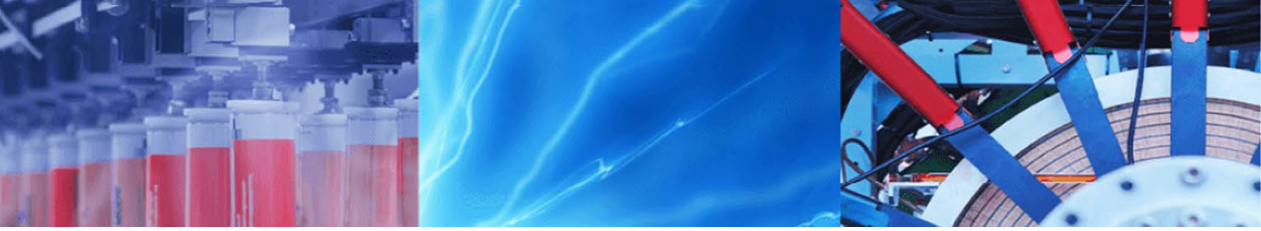

Research Article

\title{
Boron nitride nanoclusters as a sensor for Cyclosarin nerve agent: DFT and thermodynamics studies
}

\author{
Karim Derakhshan Karjabad ${ }^{1}$. Sahar Mohajeri ${ }^{1}$ [D - Ali Shamel ${ }^{1}$ - Mohammad Khodadadi-Moghaddam ${ }^{1}$. \\ Gholamreza Ebrahimzadeh Rajaei ${ }^{1}$
}

Received: 30 December 2019 / Accepted: 2 March 2020 / Published online: 7 March 2020

(c) Springer Nature Switzerland AG 2020

\begin{abstract}
To find a chemical sensor for detection of Cyclosarin (GF) nerve agent, we studied its interaction with $B_{24} \mathrm{~N}_{24}, \mathrm{AlB}_{23} \mathrm{~N}_{24}$ $B_{16} \mathrm{~N}_{16}$ and $A_{1 B}{ }_{15} N_{16}$ nanoclusters by means of density functional theory calculations. All calculations were investigated whit the M06 method and 6-311G(d,p) basis set. It was demonstrated that the interaction of GF with $\mathrm{AlB}_{23} \mathrm{~N}_{24}$ and $\mathrm{AlB}_{15} \mathrm{~N}_{16}$ is more stable than that of the $B_{24} N_{24}$ and $B_{16} N_{16}$. Thermodynamic parameters indicated that the $A_{1 B}{ }_{23} N_{24}$ and $A l B_{15} N_{16}$ interactions with the GF are exothermic and spontaneous. Despite both $\mathrm{AlB}_{23} \mathrm{~N}_{24}$ and $\mathrm{AlB}_{15} \mathrm{~N}_{16}$ demonstrated strong adsorption, the electronic properties calculation indicated that $A_{1} B_{15} N_{16}$ sensitive to the nerve agent adsorption. Our results predicted $\mathrm{AlB}_{15} \mathrm{~N}_{16}$ has good potential as a sensor for the detection of GF.
\end{abstract}

Keywords Cyclosarin · BN nanoclusters · DFT · Adsorption · Sensor

\section{Introduction}

Detection of nerve agents is an important chemical process for our safety and health [1]. Also, their identification is important for military and civilian defense resources [2]. Cyclosarin (GF) is a highly toxic organophosphate that belongs to the member of nerve used in the Gulf War (GW) operations [3,4]. Various methods introduced for nerve agent detection including chromatography [5], mass spectroscopy [6], photoluminescent [7] and fluorescent sensors [8]. By the advent of nanotechnology, nanostructures have attracted an extensive attention as gas sensors because their surface/volume ratio is much higher than that of the conventional micro sensors which makes the large adsorption area available for adsorption process [9-18]. Boron nitride (BN) nanostructures have been introduced as a capable tool for the adsorption of compounds due to their high amount of bonding energy $[19,20]$. Unlike the carbon nanostructures, the BN nanostructures are wide bandgap semiconductors, offer greater applications in electronic devices and sensors [21, 22]. Recently fullerene-like nanoclusters of BN nanostructures have attracted considerable attention [23-27].

Oku et al. $[28,29]$ have synthesized $\mathrm{B}_{16} \mathrm{~N}_{16}$ and $\mathrm{B}_{24} \mathrm{~N}_{24}$ nanoclusters, detected by laser desorption time-of flight mass spectrometry. Seifert et al. [30] indicated that the $\mathrm{B}_{16} \mathrm{~N}_{16}$ with 4 and 6 membered $\mathrm{B}-\mathrm{N}$ rings is excellent stable $\mathrm{BN}$ nanoclusters and Wu and Jiao [31] indicated that $\mathrm{B}_{24} \mathrm{~N}_{24}$ nanocluster with isolated 4, 6 and 8-membered $\mathrm{B}-\mathrm{N}$ rings are more stable than other structures of $\mathrm{B}_{24} \mathrm{~N}_{24}$. Various applications and properties of $\mathrm{B}_{16} \mathrm{~N}_{16}$ and $\mathrm{B}_{24} \mathrm{~N}_{24}$ nanoclusters have been widely studied [32-35]. For example, Shakerzadeh et al. have shown the adsorption of phosgene over the $\mathrm{B}_{12} \mathrm{~N}_{12}$ and $\mathrm{B}_{16} \mathrm{~N}_{16}$ nanoclusters using density functional theory (DFT) calculations. They reported that the $\mathrm{AlB}_{11} \mathrm{~N}_{12}$ and $\mathrm{AlB}_{15} \mathrm{~N}_{16}$ nanoclusters could be promising sensor for phosgene detection [36]. The structure and electronic properties of $\mathrm{B}_{24} \mathrm{~N}_{24}$ nanocluster functionalized with formaldehyde molecule was studied by Rostami et al. [37] using DFT calculations. They found $\mathrm{B}_{24} \mathrm{~N}_{24}$ is suitable

Sahar Mohajeri, saharmohajeri1356@gmail.com | 'Department of Chemistry, Ardabil Branch, Islamic Azad University, Ardabil, Iran. 
for formaldehyde detection. Soltani et al. have shown the adsorption of 5-AVA drug over the $\mathrm{B}_{12} \mathrm{~N}_{12}$ and $\mathrm{B}_{16} \mathrm{~N}_{16}$ nanoclusters using DFT calculations. They reported that the nanoclusters could be suitable for 5-AVA drug delivery [38]. Computational methods significantly help the experimentalist to understand different compounds behavior [39].

In this research, the interaction of GF with the $\mathrm{B}_{16} \mathrm{~N}_{16}$ and $\mathrm{B}_{24} \mathrm{~N}_{24}$ nanoclusters were surveyed by using theoretical calculations. Moreover, we doped $\mathrm{Al}$ atom instead of $B$ atom in the $\mathrm{B}_{16} \mathrm{~N}_{16}$ and $\mathrm{B}_{24} \mathrm{~N}_{24}\left(\mathrm{AlB}_{15} \mathrm{~N}_{16}\right.$ and $\left.\mathrm{AlB}_{23} \mathrm{~N}_{24}\right)$ to find the suitable gas sensor of GF nerve agent (Fig. 1). The obtained results may provide a new insight to the gas sensor nanotechnology.

\section{Computational method}

Adsorption of GF onto the $\mathrm{B}_{24} \mathrm{~N}_{24}, \mathrm{AlB}_{23} \mathrm{~N}_{24}, \mathrm{~B}_{16} \mathrm{~N}_{16}$ and $\mathrm{AlB}_{15} \mathrm{~N}_{16}$ surfaces was investigated using density functional theory (Figs. 1, 2, 3, 4, 5 and 6). All calculations were carried out using GAMESS program package [40] with the M06 method and 6-311G(d,p) basis set. The previous reports were indicated that M06 method is appropriate for predict electronic and structural properties [41, 42] and $6-311 \mathrm{G}(\mathrm{d}, \mathrm{p})$ basis set has been known suitable for nanostructure systems $[43,44]$. The adsorption energies $\left(E_{a d}\right)$ were calculated with the following equations:

$E_{a d}=E\left(G F / B_{24} N_{24}\right)-E\left(B_{24} N_{24}\right)-E(G F)+E_{B S S E}$

$E_{a d}=E\left(G F / A B_{23} N_{24}\right)-E\left(A^{\prime} B_{23} N_{24}\right)-E(G F)+E_{B S S E}$

$E_{a d}=E\left(G F / B_{16} N_{16}\right)-E\left(B_{16} N_{16}\right)-E(G F)+E_{B S S E}$

$E_{a d}=E\left(G F / A B_{15} N_{16}\right)-E\left(A_{13} N_{15}\right)-E(G F)+E_{B S S E}$

where $\mathrm{E}\left(\mathrm{GF} / \mathrm{B}_{24} \mathrm{~N}_{24}\right), \mathrm{E}\left(\mathrm{GF} / \mathrm{AlB}_{23} \mathrm{~N}_{24}\right), \mathrm{E}\left(\mathrm{GF} / \mathrm{B}_{16} \mathrm{~N}_{16}\right)$ and $\mathrm{E}(\mathrm{GF} /$ $\mathrm{AlB}_{15} \mathrm{~N}_{16}$ ) are the total energies of the $\mathrm{B}_{24} \mathrm{~N}_{24}, \mathrm{AlB}_{23} \mathrm{~N}_{24}$, $\mathrm{B}_{16} \mathrm{~N}_{16}$ and $\mathrm{AlB}_{15} \mathrm{~N}_{16}$ interacted with GF, E(GF), $\mathrm{E}\left(\mathrm{B}_{24} \mathrm{~N}_{24}\right)$, $E\left(A I B_{23} N_{24}\right), E\left(B_{16} N_{16}\right)$ and $E\left(A_{1 B}{ }_{15} N_{16}\right)$ are the total energy of the lone GF, $B_{24} \mathrm{~N}_{24}, \mathrm{AlB}_{23} \mathrm{~N}_{24}, \mathrm{~B}_{16} \mathrm{~N}_{16}$ and $\mathrm{AlB}_{15} \mathrm{~N}_{16}$, respectively. $E_{B S S E}$ is the basis set superposition error

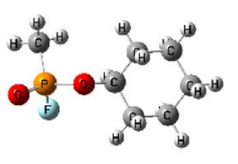

GF

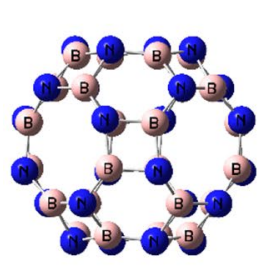

$\mathbf{B}_{24} \mathbf{N}_{24}$

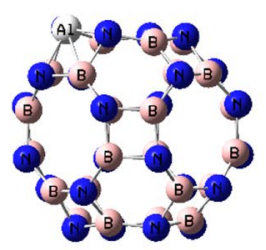

$\mathrm{AlB}_{23} \mathbf{N}_{24}$

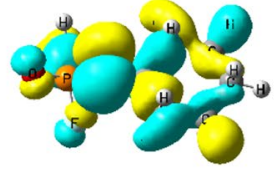

HOMO-GF

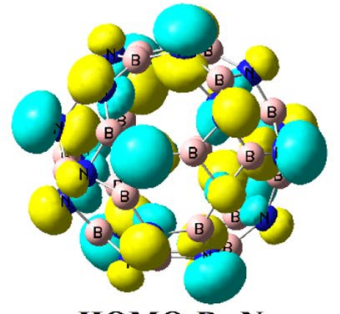

HOMO-B ${ }_{24} \mathrm{~N}_{24}$

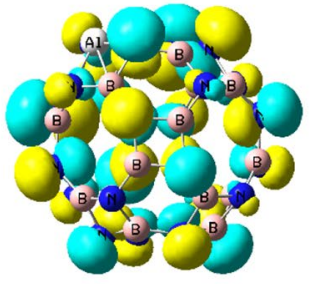

HOMO-AIB ${ }_{23} \mathrm{~N}_{24}$

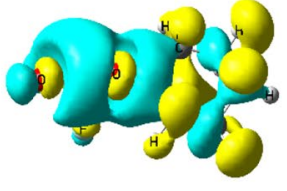

LUMO-GF

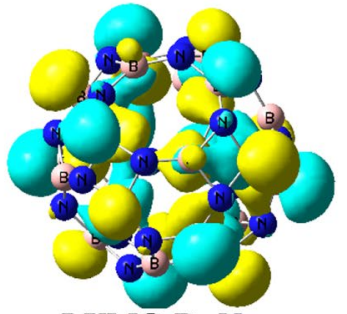

LUMO-B ${ }_{24} \mathbf{N}_{24}$

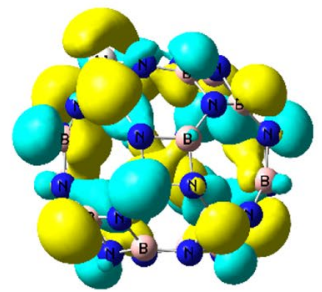

LUMO-AlB ${ }_{23} \mathrm{~N}_{24}$

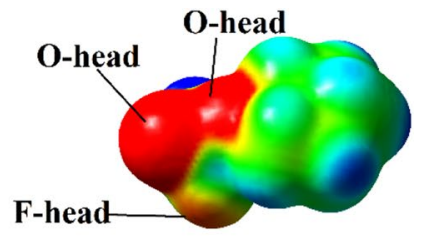

MEP-GF

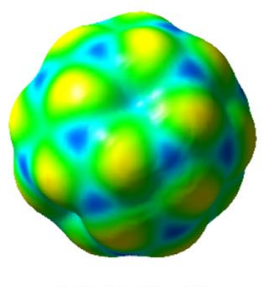

MEP-B ${ }_{24} \mathbf{N}_{24}$

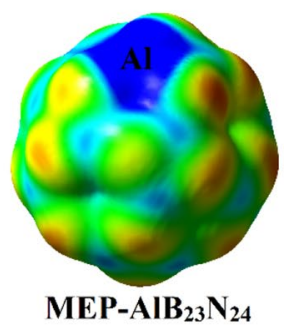

Fig. 1 Optimized configurations, the FMO (HOMO and LUMO) and MEP plots of the GF, $B_{24} \mathrm{~N}_{24}$ and $\mathrm{AlB}_{23} \mathrm{~N}_{24}$. (The color scheme for MEP surface is red-electron rich or partially negative charge; blue-

electron deficient or partially positive charge; light blue-slightly electron deficient region; yellow-slightly electron rich region, respectively) 
(BSSE) corrected for all adsorption energy [45]. The thermodynamic parameters such as Gibbs free energy $(\Delta G)$, enthalpy $(\Delta \mathrm{H})$ and entropy $(\Delta \mathrm{S})(\mathrm{T}=298.15 \mathrm{~K}$ and $\mathrm{P}=1 \mathrm{~atm})$ were investigated with the M06 method and $6-311 \mathrm{G}(\mathrm{d}, \mathrm{p})$ basis set. Furthermore, frontier molecular orbitals (FMO), molecular electrostatic potential (MEP), natural bond orbital (NBO), and density of states (DOS) analysis were computed [38].

\section{Result and discussion}

The optimized structure, FMO and MEP plots for GF were provided in Fig. 1. As shown in MEP plot, the negative charges (red color) are mainly localized over the carbonyl oxygen ( $O$ head), $F$ atom ( $F$ head) and etheric oxygen $(O$ head), which can be interacted with electrophile sites of nanocluster. The calculated $\mathrm{P}=\mathrm{O}, \mathrm{P}-\mathrm{O}$ and $\mathrm{P}-\mathrm{F}$ bond lengths were calculated $1.46,1.59$ and $1.59 \AA$, respectively. The FMO plot for GF is located on all atoms in the HOMO and LUMO regions.

\subsection{The adsorption of GF on the $B_{24} N_{24}$ and $A \mid B_{23} N_{24}$}

The most stable configuration of $\mathrm{B}_{24} \mathrm{~N}_{24}$ and $\mathrm{AlB}_{23} \mathrm{~N}_{24}$ nanoclusters was shown in Fig. 1. The calculated $\mathrm{B}-\mathrm{N}$ bond length between $6-8,6-4$ and $4-8$ membered rings are $1.42,1.49$ and $1.47 \AA$, respectively, and is completely in agreement with the previous reports $[37,46]$. The calculated Al-N bond length in $\mathrm{AlB}_{23} \mathrm{~N}_{24}$ for 6-8, 6-4 and 4-8 membered rings are $1.77,1.83$ and $1.80 \AA$, respectively. The MEP plots of the $\mathrm{B}_{24} \mathrm{~N}_{24}$ and $\mathrm{AlB}_{23} \mathrm{~N}_{24}$ indicated the electrostatic potential in the $\mathrm{Al}$ atom of $\mathrm{AlB}_{23} \mathrm{~N}_{24}$ is significantly more positive (blue color) compared to the $\mathrm{B}$ and $\mathrm{N}$ atoms which makes it the most electrophilic site for GF molecule.

The reactivity of GF with nanoclusters has been studied in the various adsorption sites (Fig. 2). The adsorption energies of GF with the $B_{24} \mathrm{~N}_{24}$ in state $A, B$ and $C$ were calculated to be -9.60 and -5.57 and $-5.51 \mathrm{kcal} \mathrm{mol}^{-1}$, respectively (Table 1 ). Nejati et al. indicated the interaction of GF with BN nanosheet with weak adsorption energies of $-0.32 \mathrm{kcal} \mathrm{mol}^{-1}$ at the B3LYP-D method and 6-31G* basis set [47]. Equilibrium distances between $\mathrm{GF}$ and nanocluster in state $A, B$ and $C$ were obtained to be $1.62,2.67$ and $2.43 \AA$, respectively. These results were

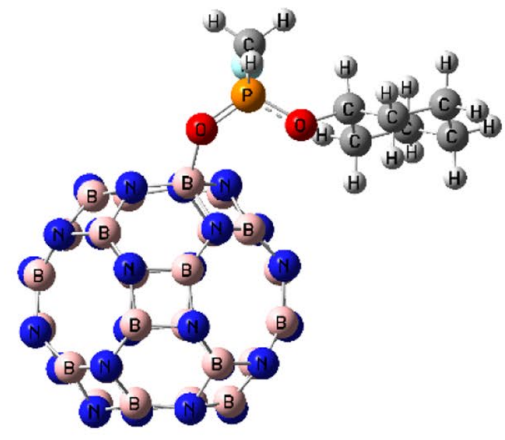

A

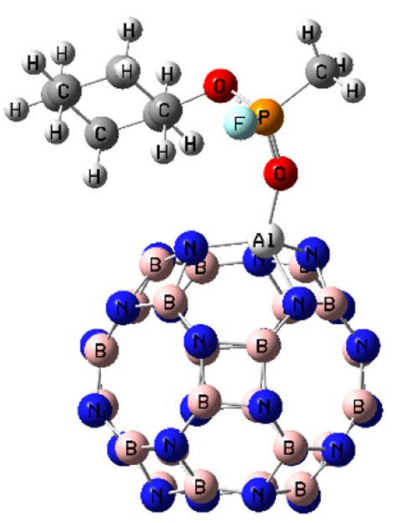

D

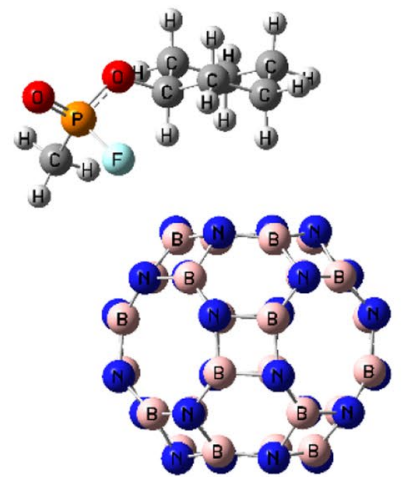

B

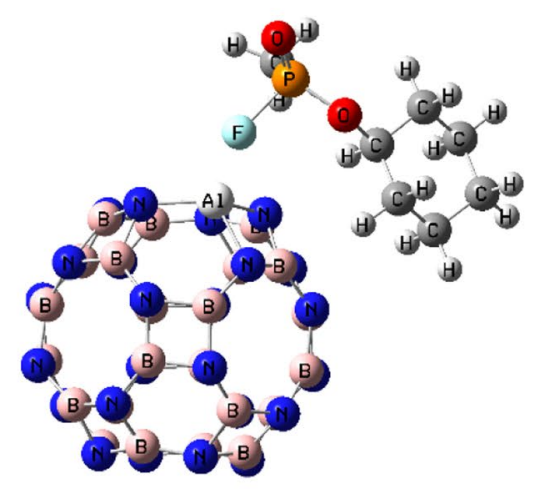

E

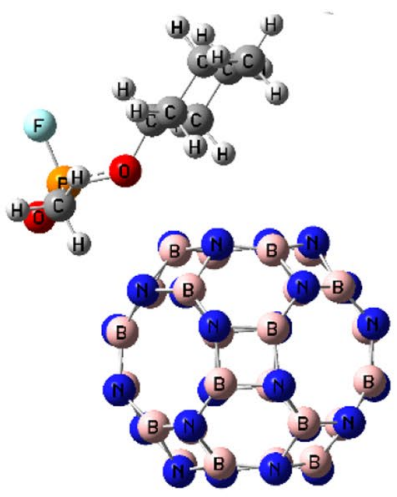

C

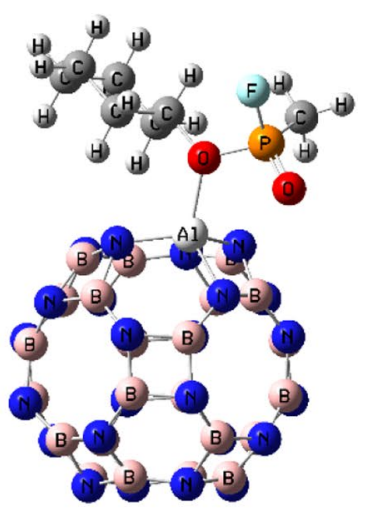

F

Fig. 2 Optimized configurations for the GF/B ${ }_{24} \mathrm{~N}_{24}$ (state $A, B$ and C) and GF/AlB ${ }_{23} \mathrm{~N}_{24}$ (state $D, E$ and F) at the M06 method 
Table 1 Calculated adsorption energy $\left(\mathrm{E}_{\mathrm{ad}} / \mathrm{kcal} \mathrm{mol}^{-1}\right)$, basis set superposition error $\left(\mathrm{E}_{\mathrm{BSSE}} / \mathrm{kcal}^{\mathrm{mol}}{ }^{-1}\right)$, bond distance between $\mathrm{GF}$ and nanocluster (D/Å), HOMO energies (HOMO/eV), LUMO energies (LUMO/eV), energy gap $\left(\mathrm{E}_{\mathrm{g}} / \mathrm{eV}\right)$, change of $\mathrm{E}_{\mathrm{g}}$ after adsorp- tion $\left(\% \Delta \mathrm{E}_{\mathrm{g}} / \%\right)$, enthalpy $\left(\Delta \mathrm{H} / \mathrm{kcal} \mathrm{mol}^{-1}\right)$, Gibbs free energy $(\Delta \mathrm{G} /$

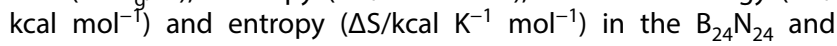
$\mathrm{AlB}_{23} \mathrm{~N}_{24}$ nanoclusters

\begin{tabular}{lllllllllll}
\hline Name & $\mathrm{E}_{\mathrm{ad}}$ & $\mathrm{E}_{\mathrm{BSSE}}$ & $\mathrm{D}$ & $\mathrm{HOMO}$ & $\mathrm{LUMO}$ & $\mathrm{E}_{\mathrm{g}}$ & $\% \Delta \mathrm{E}_{\mathrm{g}}$ & $\Delta \mathrm{H}$ & $\Delta \mathrm{G}$ & $\Delta \mathrm{S}$ \\
\hline $\mathrm{B}_{24} \mathrm{~N}_{24}$ & - & - & - & -8.10 & -1.05 & 7.04 & - & - & - \\
State A & -9.60 & 4.07 & 1.62 & -7.21 & -0.49 & 6.72 & -4.62 & -12.35 & 0.70 & -0.044 \\
State B & -5.57 & 2.22 & 2.67 & -8.20 & -1.22 & 6.98 & -0.86 & -6.32 & 5.30 & -0.039 \\
State C & -5.51 & 2.93 & 2.43 & -7.95 & -0.91 & 7.04 & -0.09 & -7.54 & 5.60 & -0.044 \\
AlB $_{23} \mathrm{~N}_{24}$ & - & - & - & -7.91 & -2.36 & 5.55 & - & - & - \\
State D & -50.63 & 4.02 & 1.83 & -7.07 & -0.62 & 6.45 & 16.30 & -52.88 & -42.54 & -0.035 \\
State E & -23.14 & 4.61 & 1.88 & -7.57 & -0.98 & 6.60 & 18.93 & -27.75 & -12.25 & -0.052 \\
State F & -30.61 & 3.89 & 1.98 & -7.37 & -0.94 & 6.44 & 16.05 & -33.62 & -18.88 & -0.049 \\
\hline
\end{tabular}

shown the interaction of state $A$ (carbonyl oxygen) is stronger than that of state $B$ ( $F$ atom) and $C$ (etheric oxygen) since adsorption energies were indicated in state $B$ is more negative than that of state $B$ and $C$. The adsorption energy of GF/AlB ${ }_{23} \mathrm{~N}_{24}$ was calculated $-50.63,-23.14$ and $-30.61 \mathrm{kcal} \mathrm{mol}^{-1}$ with equilibrium distances $1.83,1.88$ and $1.98 \AA$ in state $D, E$ and $F$, respectively. These results indicated that GF adsorption on the $\mathrm{AlB}_{23} \mathrm{~N}_{24}$ is stronger than that on the pure one. NBO charge transfers in state $D$, $E$ and $F$ were calculated $0.183,0.151$ and 0.160 e, respectively. Positive values of charge transfers are indicated charge transfer from GF to the nanoclusters.

Furthermore, the thermodynamic parameters (Gibbs free energy $(\Delta G)$, enthalpy $(\Delta H)$ and entropy $(\Delta S))$ were calculated and listed in Table 1. The $\Delta \mathrm{H}$ values for GF/ $B_{24} \mathrm{~N}_{24}$ in state $A, B$ and $C$ were calculated -12.35 , -6.32 and $-7.54 \mathrm{kcal} \mathrm{mol}^{-1}$, respectively, and in GF/ $\mathrm{AlB}_{23} \mathrm{~N}_{24}$ complexes were obtained $-52.88,-27.75$ and $-33.62 \mathrm{kcal} \mathrm{mol}^{-1}$ in state $\mathrm{D}, \mathrm{E}$ and $\mathrm{F}$, respectively. The negative values of $\Delta \mathrm{H}$ indicated that the reactions are exothermic. The $\Delta G$ values were calculated $0.70,5.30,5.60$, $-42.54,-12.25$ and $-18.89 \mathrm{kcal} \mathrm{mol}^{-1}$ in state A, B, C, D, $E$ and $F$, respectively. Therefore, $B_{24} N_{24}$ interaction is nonspontaneous while $\mathrm{AlB}_{23} \mathrm{~N}_{24}$ interaction is spontaneous.
The calculated $\Delta G$ values are less negative compared to the $\Delta \mathrm{H}$ values, indicating an entropy reduction. The calculated negative values of $\Delta S$ confirm this matter. These results were indicated the interaction of the $\mathrm{AlB}_{23} \mathrm{~N}_{24}$ is more suitable compared to the $B_{24} \mathrm{~N}_{24}$ nanocluster. The MEP plot of GF/AIB ${ }_{23} \mathrm{~N}_{24}$ in Fig. 3, shows significant change after adsorption in the electrostatic potential. These results reinforce the fact that GF gets chemically adsorbed on the $\mathrm{AlB}_{23} \mathrm{~N}_{24}$.

Some of the electronic properties like HOMO, LUMO and $E_{g}$ were reported in Table 1. The $E_{g}$ is decreased from $7.04 \mathrm{eV}$ in $\mathrm{B}_{24} \mathrm{~N}_{24}$ to $5.55 \mathrm{eV}$ in $\mathrm{AlB}_{23} \mathrm{~N}_{24}$. Salari investigated $E_{g}$ of $B_{24} \mathrm{~N}_{24} 7.11 \mathrm{eV}$ at the M06/6-31G* level of theory [48]. The HOMO and LUMO values in the $B_{24} \mathrm{~N}_{24}$ and $\mathrm{AlB}_{23} \mathrm{~N}_{24}$ nanoclusters were shifted to higher energy after adsorption (except GF/ ${ }_{24} \mathrm{~N}_{24}$ in state $B$ ). These results indicated that the adsorption of GF on the $B_{24} N_{24}$ and $A_{1 B}{ }_{23} N_{24}$ nanoclusters destabilizes the HOMO and LUMO levels. In $\mathrm{GF} / \mathrm{B}_{24} \mathrm{~N}_{24}$ complexes the $\mathrm{E}_{\mathrm{g}}$ values were revealed that no significant change compared with pure $\mathrm{B}_{24} \mathrm{~N}_{24}(-4.62 \%$, $-0.86 \%$ and $-0.09 \%$ in state $A, B$ and $C$, respectively) but in $\mathrm{GF} / \mathrm{AlB}_{23} \mathrm{~N}_{24}, \mathrm{E}_{\mathrm{g}}$ values were increased from $5.55 \mathrm{eV}$ in pure $\mathrm{AlB}_{23} \mathrm{~N}_{24}$ to $6.45,6.60$ and $6.44 \mathrm{eV}$ in state $\mathrm{D}, \mathrm{E}$ and $\mathrm{F}$, respectively. The DOS plot of the pure $\mathrm{AlB}_{23} \mathrm{~N}_{24}$ and
Fig. 3 MEP plot for GF/AIB ${ }_{23} \mathrm{~N}_{24}$ in state $D$ and the DOS plot for pure $\mathrm{AlB}_{23} \mathrm{~N}_{24}$ and $\mathrm{GF} / \mathrm{B}_{23} \mathrm{~N}_{24}$ in state $D$
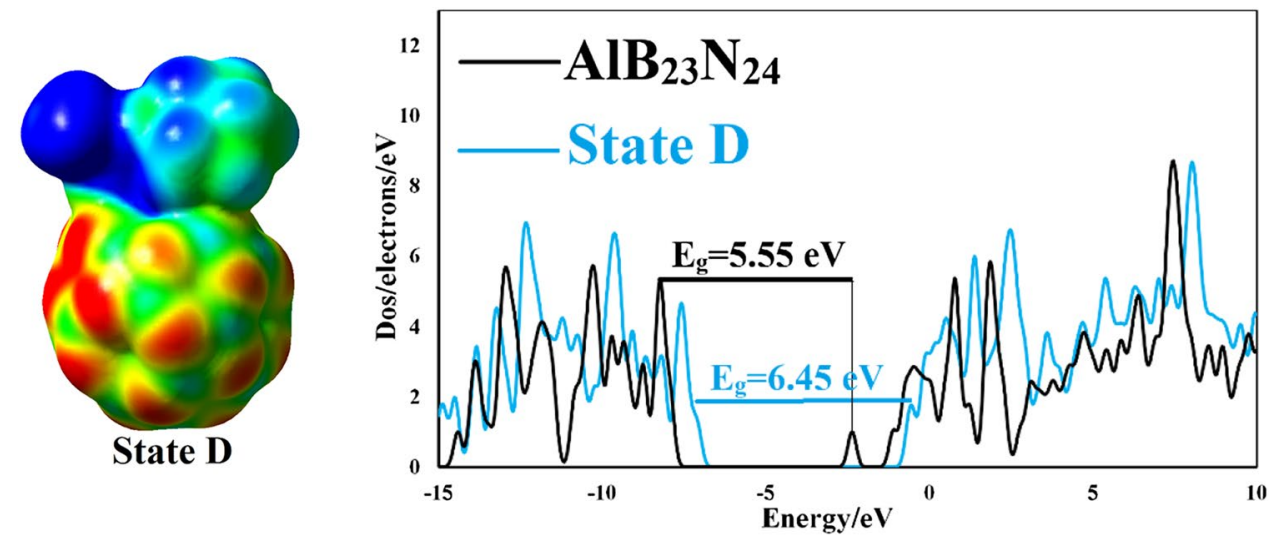
GF/AIB ${ }_{23} \mathrm{~N}_{24}$ in state $\mathrm{D}$ indicated this change (Fig. 3). The change of $E_{g}$ will exponentially increase the sensitivity and electrical conductivity of the nanostructure [49-51]. Therefore, it is clear that the GF/AlB ${ }_{23} \mathrm{~N}_{24}$ is more sensitive rather than $\mathrm{B}_{24} \mathrm{~N}_{24}$. change of $\mathrm{E}_{\mathrm{g}}$ indicated that the $\mathrm{AlB}_{23} \mathrm{~N}_{24}$ can detect the GF.

\subsection{The adsorption of GF on the $B_{16} N_{16}$ and $A \mid B_{15} N_{16}$}

Furthermore, we examined adsorption of GF molecule on the $\mathrm{B}_{16} \mathrm{~N}_{16}$ and $\mathrm{AlB}_{15} \mathrm{~N}_{16}$ nanoclusters. The optimized structures, MEP and FMO plots of $\mathrm{B}_{16} \mathrm{~N}_{16}$ and $\mathrm{AlB}_{15} \mathrm{~N}_{16}$ are shown in Fig. 4. The $\mathrm{B}-\mathrm{N}$ bond lengths of $\mathrm{B}_{16} \mathrm{~N}_{16}$ in 6-6 and 6-4 membered rings were calculated 1.45 and $1.47 \AA$, respectively and $\mathrm{Al}-\mathrm{N}$ bond lengths for $\mathrm{AlB}_{15} \mathrm{~N}_{16}$ were calculated 1.80 and $1.81 \AA$ in $6-6$ and $6-4$ membered rings, respectively.

After adsorption of GF on the $\mathrm{B}_{16} \mathrm{~N}_{16}$, adsorption energies were calculated $-14.30,-1.46$ and $-16.52 \mathrm{kcal} \mathrm{mol}^{-1}$ in state $\mathrm{G}, \mathrm{H}$ and I, respectively (Table 2 ). When $\mathrm{GF}$ is located from its etheric oxygen (state I) on the $\mathrm{B}_{16} \mathrm{~N}_{16}$ nanocluster, it reoriented and attached from carbonyl oxygen to the $B_{16} \mathrm{~N}_{16}$ (Fig. 5). Equilibrium distances in state $\mathrm{G}, \mathrm{H}$ and I were calculated $1.59,2.53$ and $1.57 \AA$, respectively. The adsorption energies of $\mathrm{AlB}_{15} \mathrm{~N}_{16}$ complexes were obtained $-54.84,-28.28$ and $-35.22 \mathrm{kcal} \mathrm{mol}^{-1}$ in state

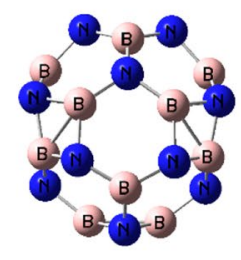

$\mathbf{B}_{16} \mathbf{N}_{16}$

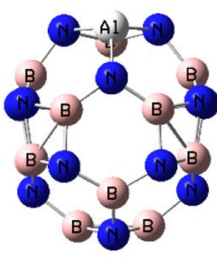

$\mathrm{AlB}_{23} \mathbf{N}_{24}$

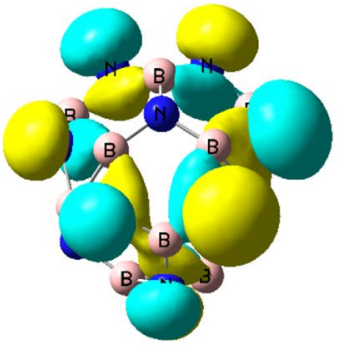

HOMO-B ${ }_{16} \mathbf{N}_{16}$

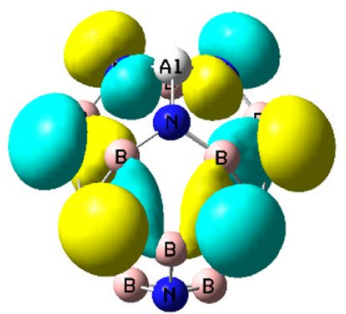

HOMO-AIB ${ }_{23} \mathrm{~N}_{24}$

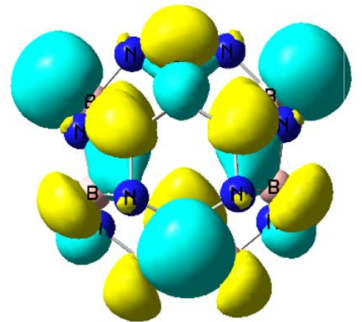

LUMO-B ${ }_{16} \mathbf{N}_{16}$

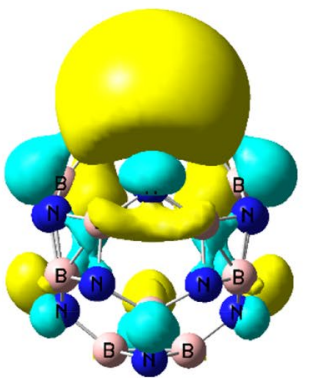

LUMO-AIB ${ }_{23} \mathrm{~N}_{24}$

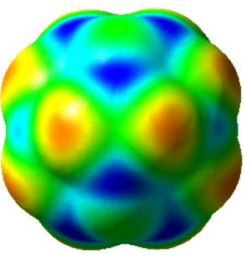

MEP-B ${ }_{16} \mathbf{N}_{16}$

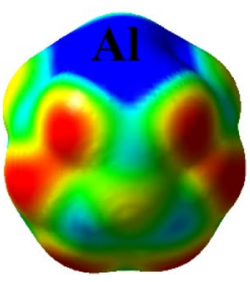

MEP-AIB ${ }_{23} \mathbf{N}_{24}$

Fig. 4 Optimized configurations, the FMO (HOMO and LUMO) and MEP plots of the $\mathrm{B}_{16} \mathrm{~N}_{16}$ and $\mathrm{AIB}_{15} \mathrm{~N}_{16}$

Table 2 Calculated adsorption energy $\left(E_{a d} / \mathrm{kcal} \mathrm{mol}^{-1}\right)$, basis set superposition error $\left(\mathrm{E}_{\mathrm{BSSE}} / \mathrm{kcal}^{\mathrm{mol}}{ }^{-1}\right)$, bond distance between $\mathrm{GF}$ and nanocluster (D/Å), HOMO energies (HOMO/eV), LUMO energies $(\mathrm{LUMO} / \mathrm{eV})$, energy gap $\left(\mathrm{E}_{\mathrm{g}} / \mathrm{eV}\right)$, change of $\mathrm{E}_{\mathrm{g}}$ after adsorp- tion $\left(\% \Delta \mathrm{E}_{\mathrm{g}} / \%\right)$, enthalpy $\left(\Delta \mathrm{H} / \mathrm{kcal} \mathrm{mol}^{-1}\right)$, Gibbs free energy ( $\Delta \mathrm{G} /$

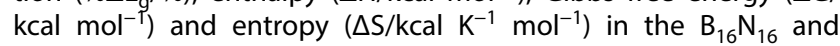
$\mathrm{AlB}_{15} \mathrm{~N}_{16}$ nanoclusters

\begin{tabular}{lllllllllll}
\hline Name & $\mathrm{E}_{\mathrm{ad}}$ & $\mathrm{E}_{\mathrm{BSSE}}$ & $\mathrm{D}$ & $\mathrm{HOMO}$ & $\mathrm{LUMO}$ & $\mathrm{E}_{\mathrm{g}}$ & $\% \Delta \mathrm{E}_{\mathrm{g}}$ & $\Delta \mathrm{H}$ & $\Delta \mathrm{G}$ & $\Delta \mathrm{S}$ \\
\hline $\mathrm{B}_{16} \mathrm{~N}_{16}$ & - & - & - & -8.06 & -1.25 & 6.82 & -3.15 & - & - \\
State G & -14.30 & 3.98 & 1.59 & -6.95 & -0.35 & 6.60 & -0.59 & -17.86 & -3.94 & -0.047 \\
State H & -1.46 & 1.53 & 2.53 & -7.83 & -1.05 & 6.77 & -2.71 & -2.19 & 9.80 & -0.040 \\
State I & -16.52 & 4.75 & 1.57 & -7.12 & -0.49 & 6.63 & - & -19.76 & -6.12 & -0.046 \\
AlB $_{15} \mathrm{~N}_{16}$ & & - & - & -7.65 & -3.06 & 4.59 & - & - & - & - \\
State J & -54.84 & 4.20 & 1.82 & -6.63 & -0.71 & 5.92 & 29.00 & -57.53 & -45.79 & -0.039 \\
State K & -28.28 & 4.85 & 1.86 & -7.25 & -1.15 & 6.09 & 32.71 & -32.06 & -20.22 & -0.040 \\
State L & -35.22 & 4.42 & 1.93 & -7.00 & -0.58 & 6.42 & 39.95 & -38.80 & -24.64 & -0.047 \\
\hline
\end{tabular}




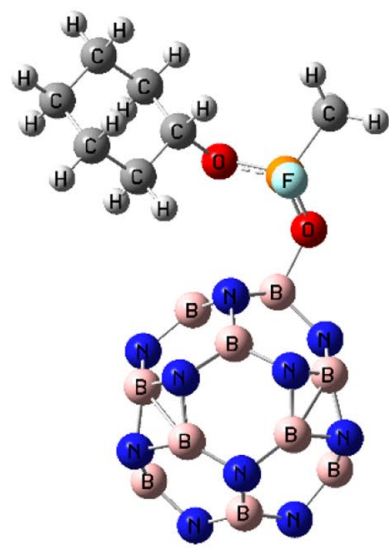

G

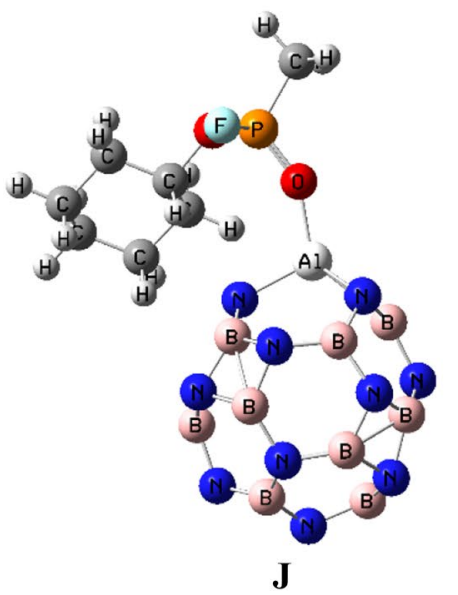

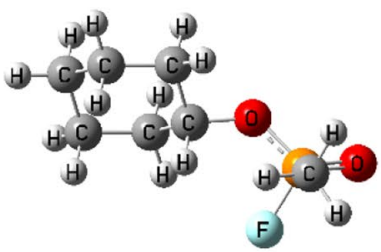

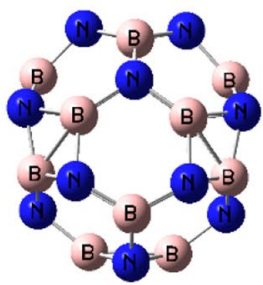

H
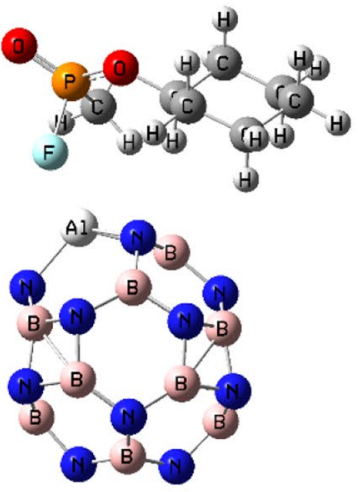

$\mathbf{K}$
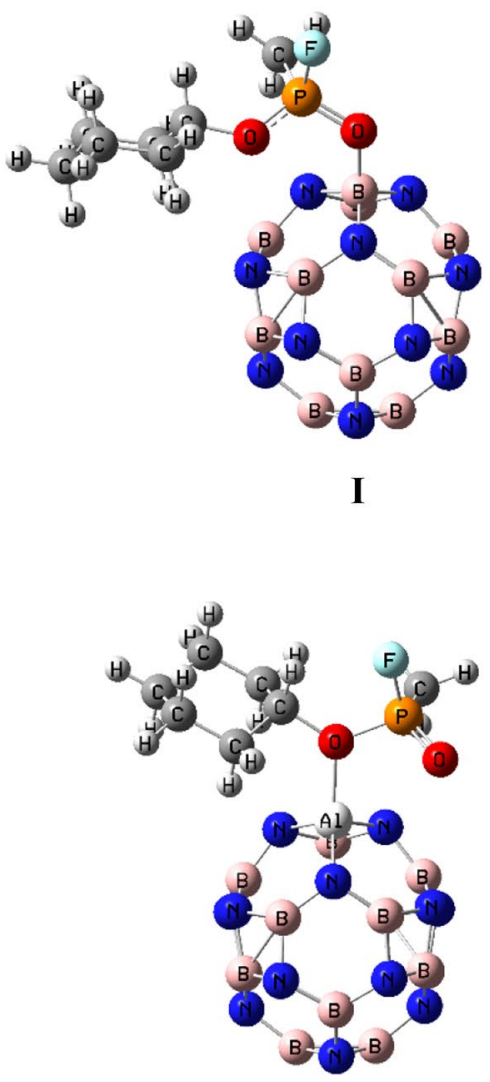

$\mathbf{L}$

Fig. 5 Optimized configurations for the $\mathrm{GF} / \mathrm{B}_{16} \mathrm{~N}_{16}$ (state $\mathrm{G}, \mathrm{H}$ and I) and GF/AlB ${ }_{15} \mathrm{~N}_{16}$ (state J, K and L) at the M06 method

Fig. 6 MEP plot for GF/AIB ${ }_{15} \mathrm{~N}_{16}$ in state $J$ and the DOS plot for pure $\mathrm{AlB}_{15} \mathrm{~N}_{16}$ and GF/B ${ }_{15} \mathrm{~N}_{16}$ in state $\mathrm{J}$
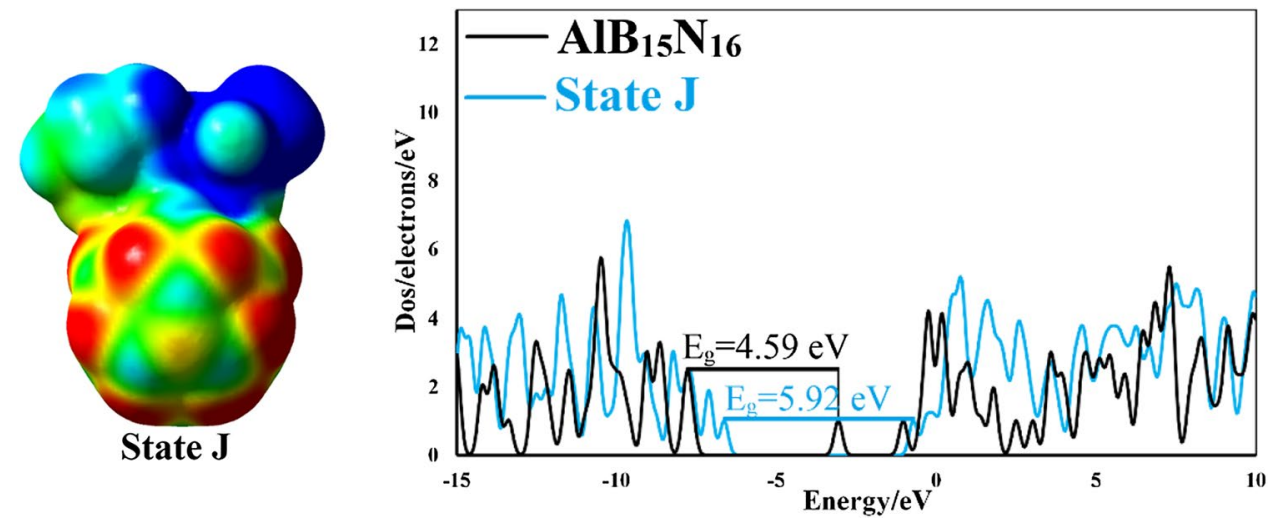

The $\Delta \mathrm{H}(\Delta \mathrm{G})$ values of $\mathrm{GF} / \mathrm{B}_{16} \mathrm{~N}_{16}$ and $\mathrm{GF} / \mathrm{AlB}_{15} \mathrm{~N}_{16}$ were calculated - $17.86(-3.94),-2.19(9.80),-19.76(-6.12)$, $-57.53(-45.79),-32.06(-20.22)$ and $-38.80(-24.63)$ kcal mol ${ }^{-1}$ in state $\mathrm{G}, \mathrm{H}, \mathrm{I}, \mathrm{J}, \mathrm{K}$ and $\mathrm{L}$, respectively. The negative values of $\Delta \mathrm{H}$ and $\Delta \mathrm{G}$ indicated the reactions are exothermic and spontaneous. Upon adsorption of GF on
$\mathrm{J}, \mathrm{K}$ and $\mathrm{L}$, respectively. These results were indicated the interaction of the $A I B_{15} N_{16}$ nanocluster is stronger than that of the $\mathrm{B}_{24} \mathrm{~N}_{24}, \mathrm{AlB}_{23} \mathrm{~N}_{24}$ and $\mathrm{B}_{16} \mathrm{~N}_{16}$ nanoclusters. NBO charge transfer were calculated $0.190,0.157$ and 0.176 e and equilibrium distances were investigated $1.82,1.86$ and $1.93 \AA$ in state J, K and L, respectively.

\section{SN Applied Sciences}


$\mathrm{AlB}_{15} \mathrm{~N}_{16}$ in state J, their MEP changes significantly. These results confirm the fact that GF gets chemically adsorbed on the $\mathrm{AlB}_{15} \mathrm{~N}_{16}$.

The HOMO, LUMO and $\mathrm{E}_{\mathrm{g}}$ values for $\mathrm{B}_{16} \mathrm{~N}_{16}$ and $\mathrm{AlB}_{15} \mathrm{~N}_{16}$ at the M06 method were shown in Table 2. The HOMO values for the $\mathrm{B}_{16} \mathrm{~N}_{16}$ and $\mathrm{AlB}_{15} \mathrm{~N}_{16}$ were -8.06 and $-7.65 \mathrm{eV}$ while the LUMO values were -1.25 and $-3.06 \mathrm{eV}$, respectively. The $E_{g}$ is decreased from $6.82 \mathrm{eV}$ in $\mathrm{B}_{16} \mathrm{~N}_{16}$ to $4.59 \mathrm{eV}$ in $\mathrm{AlB}_{15} \mathrm{~N}_{16}$. Soltani et al. calculated $\mathrm{E}_{\mathrm{g}}$ of $\mathrm{B}_{16} \mathrm{~N}_{16} 6.37 \mathrm{eV}$ at the B3LYP method [52] and Shakerzadeh et al. investigated $\mathrm{E}_{\mathrm{g}}$ of $\mathrm{B}_{16} \mathrm{~N}_{16}$ and $\mathrm{AlB}_{15} \mathrm{~N}_{16} 6.17$ and $3.97 \mathrm{eV}$ at the M06-2X method [36]. The HOMO and LUMO values after adsorption process were increased to higher energy and destabilizes the HOMO and LUMO levels. $\mathrm{E}_{\mathrm{g}}$ values after adsorption in $\mathrm{GF} / \mathrm{B}_{16} \mathrm{~N}_{16}$ reveal that no significant change compared with pure $\mathrm{B}_{16} \mathrm{~N}_{16}$ and indication of $\mathrm{B}_{16} \mathrm{~N}_{16}$ nanocluster cannot detect the GF. The $E_{g}$ values are increased from $4.59 \mathrm{eV}$ in $\mathrm{AlB}_{15} \mathrm{~N}_{16}$ to 5.92, 6.09 and $6.42 \mathrm{eV}$ in state $\mathrm{J}, \mathrm{K}$ and L, respectively. Compared to the $\mathrm{B}_{24} \mathrm{~N}_{24}, \mathrm{AlB}_{23} \mathrm{~N}_{24}$ and $B_{16} N_{16}$, the $E_{g}$ represent more sensitivity in $A_{1 B}{ }_{15} N_{16}$ (29.00\% in state $J, 32.71 \%$ in state $\mathrm{K}$ and $39.95 \%$ in state $\mathrm{L}$ ). The DOS plot of $\mathrm{AlB}_{15} \mathrm{~N}_{16}$ and GF/B ${ }_{15} \mathrm{~N}_{16}$ in state J in Fig. 6 confirm this increase. The change of $E_{g}$ was indicated the $\mathrm{AlB}_{15} \mathrm{~N}_{16}$ nanocluster can detect the GF nerve agent.

\section{Conclusions}

In this study, the adsorption of the GF nerve agent on the $\mathrm{B}_{24} \mathrm{~N}_{24}, \mathrm{AlB}_{23} \mathrm{~N}_{24}, \mathrm{~B}_{16} \mathrm{~N}_{16}$ and $\mathrm{AlB}_{15} \mathrm{~N}_{16}$ was investigated using DFT calculations. The doped atom $\left(\mathrm{AlB}_{23} \mathrm{~N}_{24}\right.$ and $\mathrm{AlB}_{15} \mathrm{~N}_{16}$ ) nanoclusters facilitate the interaction of the GF compared to the pure $\mathrm{B}_{24} \mathrm{~N}_{24}$ and $\mathrm{B}_{16} \mathrm{~N}_{16}$ nanoclusters. Thermodynamic calculations were indicated adsorption of GF on the $\mathrm{AlB}_{23} \mathrm{~N}_{24}$ and $\mathrm{AlB}_{15} \mathrm{~N}_{16}$ in all states are exothermic and spontaneous. The results of $\mathrm{E}_{g}$ and DOS plots were shown that the $\mathrm{AlB}_{15} \mathrm{~N}_{16}$ has greater sensitivity to the GF than the $\mathrm{B}_{24} \mathrm{~N}_{24}, \mathrm{AlB}_{23} \mathrm{~N}_{24}$ and $\mathrm{B}_{16} \mathrm{~N}_{16}$. Therefore, the $\mathrm{AlB}_{15} \mathrm{~N}_{16}$ may be used in $\mathrm{GA}$ sensor devices.

\section{Compliance with ethical standards}

Conflict of interest The authors declare that they have no known competing financial interests or personal relationships that could have appeared to influence the work reported in this paper.

\section{References}

1. Mandal D, Mondal B, Das AK (2010) Isomerization and decomposition of a model nerve agent: a computational analysis of the reaction energetics and kinetics of dimethyl ethylphosphonate. J Phys Chem A 114(39):10717-10725
2. Dawson RM (1994) Review of oximes available for treatment of nerve agent poisoning. J Appl Toxicol 14(5):317-331

3. Heaton KJ, Palumbo CL, Proctor SP, Killiany RJ, YurgelunTodd DA, White RF (2007) Quantitative magnetic resonance brain imaging in US army veterans of the 1991 Gulf War potentially exposed to sarin and cyclosarin. Neurotoxicology 28(4):761-769

4. Kuca K, Pícha J, Jun D (2006) Reactivation potency of new group of acetylcholinesterase reactivators and their comparison with currently available oximes. Acta Medica (Hradec Kralove) 49(4):233-235

5. Kientz CE (1998) Chromatography and mass spectrometry of chemical warfare agents, toxins and related compounds: state of the art and future prospects. J Chromatogr A 814(1-2):1-23

6. Black RM, Clarke RJ, Read RW, Reid MTJ (1994) Application of gas chromatography-mass spectrometry and gas chromatographytandem mass spectrometry to the analysis of chemical warfare samples, found to contain residues of the nerve agent sarin, sulphur mustard and their degradation products. J Chromatogr A 662(2):301-321

7. Kim S, Cho B, Sohn H (2012) Detection of nerve agent stimulants based on photoluminescent porous silicon interferometer. Nanoscale Res Lett 7:1-6

8. Dale TJ, Rebek J Jr (2006) Fluorescent sensors for organophosphorus nerve agent mimics. J Am Chem Soc 128(14):4500-4501

9. Cui Y, Wei Q, Park H, Lieber CM (2001) Nanowire nanosensors for highly sensitive and selective detection of biological and chemical species. Science 293(5533):1289-1292

10. Peyghan AA, Moradi M (2014) Influence of antisite defect upon decomposition of nitrous oxide over graphene-analogue SiC. Thin Solid Films 552:111-115

11. Jha S, Wang HE, Kutsay O, Jelenković EV, Chen KJ, Bello I, Kremnican V, Zapien JA (2012) Exploiting nanostructure-thin film interfaces in advanced sensor device configurations. Vacuum 86(6):757-760

12. Eslami M, Peyghan AA (2015) DNA nucleobase interaction with graphene like BC3 nano-sheet based on density functional theory calculations. Thin Solid Films 589:52-56

13. Peyghan AA, Rastegar SF, Hadipour NL (2014) DFT study of NH3 adsorption on pristine, $\mathrm{Ni}$ - and Si-doped graphynes. Phys Lett Sect A Gen At Solid State Phys 378(30-31):2184-2190

14. Dos Santos RB, Mota FDB, Rivelino R, Kakanakova-Georgieva A, Gueorguiev GK (2016) Van der Waals stacks of few-layer h-AIN with graphene: an ab initio study of structural, interaction and electronic properties. Nanotechnology 27(14):145601

15. Rad AS (2018) Comparison of $X 12 Y 12(X=A I, B$ and $y=N, P)$ fullerene-like nanoclusters toward adsorption of dimethyl ether. J Theor Comput Chem. https://doi.org/10.1142/S021963361 8500128

16. Salimifard M, Rad AS, Mahanpoor K (2017) Surface interaction of $\mathrm{H}_{2} \mathrm{~S}, \mathrm{SO}_{2}$, and $\mathrm{SO}_{3}$ on fullerene-like gallium nitride $(\mathrm{GaN})$ nanostructure semiconductor. Solid State Commun 265:6-11

17. Rad AS, Aghaei SM, Aali E, Peyravi M (2017) Study on the electronic structure of $\mathrm{Cr}$ - and $\mathrm{Ni}$-doped fullerenes upon adsorption of adenine: a comprehensive DFT calculation. Diam Relat Mater 77:116-121

18. Rad AS, Ayub K (2017) $\mathrm{O}_{3}$ and $\mathrm{SO}_{2}$ sensing concept on extended surface of B12N12 nanocages modified by Nickel decoration: a comprehensive DFT study. Solid State Sci 69:22-30

19. Chang CM, Jalbout AF (2010) Metal induced amino acid adsorption on nanotubes. Thin Solid Films 518(8):2070-2076

20. Mirzaei M, Yousefi M (2013) Modified $(n, 0) B N$ nanotubes $(n=3-10)$ by acetic acids: DFT studies. Superlattices Microstruct $55: 1-7$

21. Guo G, Lin J (2005) Systematic ab initio study of the optical properties of BN nanotubes. Phys Rev B 71(16):165402 
22. Solimannejad $M$, Noormohammadbeigi $M(2017)$ Boron nitride nanotube (BNNT) as a sensor of hydroperoxyl radical (HO2): A DFT study. J Iran Chem Soc 14(2):471-476

23. Paine RT, Narula CK (1990) Synthetic routes to boron nitride. Chem Rev 90(1):73-91

24. Wu HS, Zhang FQ, Xu XH, Zhang CJ, Jiao H (2003) Geometric and energetic aspects of aluminum nitride cages. J Phys Chem A 107(1):204-209

25. Zhu HY, Schmalz TG, Klein DJ (1997) Alternant boron nitride cages: a theoretical study. Int J Quantum Chem 63(2):393-401

26. Golberg D, Bando Y, Stéphan O, Kurashima K (1998) Octahedral boron nitride fullerenes formed by electron beam irradiation. Appl Phys Lett 73(17):2441-2443

27. Wang Q, Sun Q, Jena P, Kawazoe Y (2009) Potential of AIN nanostructures as hydrogen storage materials. ACS Nano 3(3):621-626

28. Oku T, Nishiwaki A, Narita I, Gonda M (2003) Formation and structure of B24N24 clusters. Chem Phys Lett 380(5-6):620-623

29. Oku T, Nishiwaki A, Narita I (2004) Formation and atomic structures of $\mathrm{BnNn}(\mathrm{n}=24-60)$ clusters studied by mass spectrometry, high-resolution electron microscopy and molecular orbital calculations. Phys B Condens Matter 351(1-2):184-190

30. Seifert G, Fowler PW, Mitchell D, Porezag D, Frauenheim T (1997) Boron-nitrogen analogues of the fullerenes: electronic and structural properties. Chem Phys Lett 268(5-6):352-358

31. Wu HS, Jiao H (2004) What is the most stable B24N24 fullerene? Chem Phys Lett 386(4-6):369-372

32. Ma Z, Zhang Y, Li F, Chen H (2016) Comparative study of $\mathrm{H} 2$ adsorption on B24N24, Al24N24 and B12Al12N24 clusters. Comput Mater Sci 117:71-75

33. Koi N, Oku T, Suganuma KS (2005) Effects of endohedral element in B24N24 clusters on hydrogenation studied by molecular orbital calculations. Physica E 29(3-4):541-545

34. Rouzbehani GM, Boshra A, Seif A (2009) B24N24 nanocages: a GIAO density functional theory study of $14 \mathrm{~N}$ and $11 \mathrm{~B}$ nuclear magnetic shielding and electric field gradient tensors. Monatsh Chem 140(3):255-263

35. Mileev MA, Kuzmin SM, Parfenyuk VI (2006) Ab initio calculations of structure and stability of small boron nitride clusters. J Struct Chem 47(6):1016-1021

36. Shakerzadeh E, Khodayar E, Noorizadeh S (2016) Theoretical assessment of phosgene adsorption behavior onto pristine, Al- and Ga-doped B12N12 and B16N16 nanoclusters. Comput Mater Sci 118:155-171

37. Rostami Z, Pashangpour M, Moradi R (2017) DFT study on the chemical sensing properties of B24N24 nanocage toward formaldehyde. J Mol Graph Model 72:129-135

38. Soltani A, Sousaraei A, Bezi Javan M, Eskandari M, Balakheyli H (2016) Electronic and optical properties of 5-AVA-functionalized BN nanoclusters: a DFT study. New J Chem 40(8):7018-7026

39. Pargolghasemi $P$, Saleh Hoseininezhad-Namin M, Parchehbaf Jadid A (2017) Prediction of activities of BRAF (V600E) inhibitors by SW-MLR and GA-MLR methods. Curr Comput aided Drug Design 13(3):249-261
40. Schmidt MW, Baldridge KK, Boatz JA, Elbert ST, Gordon MS, Jensen JH, Koseki S, Matsunaga N, Nguyen KA, Su S, Windus TL, Dupuis M, Montgomery JA Jr (1993) General atomic and molecular electronic structure system. J Comput Chem 14(11):1347-1363

41. Walker M, Harvey AJA, Sen A, Dessent CEH (2013) Performance of M06, M06-2X, and M06-HF density functionals for conformationally flexible anionic clusters: M06 functionals perform better than B3LYP for a model system with dispersion and ionic hydrogen-bonding interactions. J Phys Chem A 117(47):12590-12600

42. Rostami Z, Hosseinian A, Monfared A (2018) DFT results against experimental data for electronic properties of C60 and C70 fullerene derivatives. J Mol Graph Model 81:60-67

43. Kazemi M, Rad AS (2017) Sulfur mustard gas adsorption on ZnO fullerene-like nanocage: Quantum chemical calculations. Superlattices Microstruct 106:122-128

44. Deng WQ, Xu X, Goddard WA (2004) New alkali doped pillared carbon materials designed to achieve practical reversible hydrogen storage for transportation. Phys Rev Lett 92(16):166103-1-166103-4

45. Boys SF, Bernardi F (1970) The calculation of small molecular interactions by the differences of separate total energies. Some procedures with reduced errors. Mol Phys 19(4):553-566

46. Hazrati MK, Javanshir Z, Bagheri Z (2017) B24N24 fullerene as a carrier for 5-fluorouracil anti-cancer drug delivery: DFT studies. J Mol Graph Model 77:17-24

47. Nejati K, Arshadi S, Vessally E, Bekhradnia A, Hosseinian A (2017) Cyclosarin nerve agent interaction with the pristine, Stone Wales defected, and Si-doped BN nanosheets: theoretical study. Physica E 90:143-148

48. Salari AA (2017) Are the inorganic B24N24, Al24N24, B24P24 and Al24P24 nanoclusters synthesizable or not? A DFT study. Inorg Chim Acta 456:18-23

49. Hoseininezhad-Namin MS, Pargolghasemi P, Alimohammadi S, Rad AS, Taqavi L (2017) Quantum Chemical Study on the adsorption of metformin drug on the surface of pristine, Si- and Aldoped $(5,5)$ SWCNTs. Physica E 90:204-213

50. Soltani A, Javan MB, Hoseininezhad-Namin MS, Tajabor N, Lemeski ET, Pourarian F (2017) Interaction of hydrogen with $\mathrm{Pd}$ - and co-decorated C24 fullerenes: density functional theory study. Synth Metals 234:1-8

51. Safari L, Vessally E, Bekhradnia A, Hosseinian A, Edjlali L (2017) A Density functional theory study of the sensitivity of two-dimensional BN nanosheet to nerve agents cyclosarin and tabun. Thin Solid Films 623:157-163

52. Soltani A, Baei MT, Tazikeh Lemeski E, Pahlevani AA (2014) The study of SCN-adsorption on B12N12and B16N16nano-cages. Superlattices Microstruct 75:716-724

Publisher's Note Springer Nature remains neutral with regard to jurisdictional claims in published maps and institutional affiliations. 